\title{
ARGUMENTAÇÃO JURÍDICA E ARGUMENTAÇÃO LINGUÍSTICA: QUANDO A LÍNGUA EM USO REVELA PRECONCEITOS
}

\author{
Daiane Valerio \\ Universidade do Vale do Taquari - Univates (Brasil) \\ daia_valerio83@hotmail.com \\ Kári Lúcia Forneck \\ Universidade do Vale do Taquari - Univates (Brasil) \\ kari@univates.br
}

Recebido: 04/05/2020 - Aprovado: 18/06/2020 - Publicado: 15/04/2021

DOI: doi.org/10.17533/udea.lyl.n79a14

\begin{abstract}
Resumo: Com base na teoria da argumentação na língua, este trabalho teve como proposta investigar a argumentação jurídica, sob o viés da concepção da argumentação linguística, em sentenças de crimes cometidos contra mulheres, para evidenciar se havia indícios de possíveis resquícios de enunciação de caráter preconceituoso. Foram requisitadas as dez últimas sentenças julgadas de cada ano (2014-2018), de uma comarca do Rio Grande do Sul (Brasil). Através da análise dos encadeamentos argumentativos, pôde-se chegar a uma interface entre a argumentação linguística e jurídica, evidenciando que há enunciados e enunciadores que ainda acabam propagando discursos preconceituosos contra a mulher.
\end{abstract}

Palavras-chave: linguagem jurídica; teoria da argumentação na língua; argumentação linguística; preconceito de gênero.

\section{LEGAL ARGUMENTS AND LINGUISTIC ARGUMENTS: WHEN THE LANGUAGE IN USE REVEALS PREJUDICES}

\begin{abstract}
Based on the theory of argumentation in language, this work studied the legal argumentation under the principles of linguistic argumentation, in sentences of crimes committed against women, to evidence if there were indications of possible remnants of biased enunciation. The last ten sentences judged for each year (2014-2018) were requested from a district court from the state of Rio Grande do Sul (Brazil). Through the analysis of the argumentative chains, it was possible to reach an interface between linguistic and legal arguments, showing utterances and enunciators that still end up propagating prejudiced discourses against women.
\end{abstract}

Key words: legal language; theory of argumentation in language; linguistic argumentation; gender prejudice. 
Argumentação jurídica e argumentação linguística: quando a língua em uso revela preconceitos

\section{Introdução}

linguagem é um fator indispensável para a vida em sociedade. Não apenas no sentido de seu uso como
parte de uma estrutura formal, mas na possibilidade de, através dela e com auxílio dela, poder entender e
ser entendido. É pelo poder da linguagem e com a capacidade de comunicação que os discursos ganham força e garantem as construções de sentido naquilo que se quer dizer.

Assim, a partir do estudo da Teoria da Argumentação na Língua (ANL) proposta por Oswald Ducrot e JeanClaude Anscombre (1983), continuada por Oswald Ducrot e Marion Carel, na teoria dos blocos semânticos, surge a percepção de que tudo aquilo que é falado ou escrito pode gerar novos enunciados ou fazer com que esses enunciados possam ser compreendidos. O mais surpreendente disso é que essa percepção pode ser comprovada através do estudo dos encadeamentos argumentativos da própria língua que são utilizadas no momento da enunciação. Segundo Ducrot (1981, p. 10-11), «o linguista, ao descrever uma língua, tem a obrigação de indicar quais enunciados podem ser inferidos logicamente uns dos outros». Dessa forma, este artigo busca identificar enunciados que são construídos a partir de outros em um contexto argumentativo, usando como foco de análise dessa descrição a linguagem jurídica.

Desse modo, sabendo que a linguagem jurídica está carregada de encadeamentos argumentativos que se moldam entre a acusação e a defesa, este artigo também tem o intuito de elucidar exemplos de que esses encadeamentos utilizados na linguagem jurídica podem, ainda que de forma implícita, ir contra os preceitos da justiça e, inevitavelmente, mesmo que sem intenção, denotar discurso preconceituoso contra o gênero feminino.

A escolha dessa temática parte, principalmente, da convicção de que, apesar de todos os avanços relacionados à igualdade de gênero, ainda pode-se perceber, atualmente, situações e contextos em que a mulher, exclusivamente por ser mulher, sofre com o preconceito e a desigualdade de direitos e oportunidades. Não bastasse isso, a mulher, recorrentemente, é vítima de casos em que a violência é um dos marcos finais de uma série de abusos cometidos por homens agressores que, na maioria dos casos, são seus próprios companheiros.

Diante desses abusos, foi sancionada, no dia 07 de agosto de 2006, a lei n. 11. 340/2006, conhecida como a Lei Maria da Penha, que «Cria mecanismos para coibir a violência doméstica e familiar contra a mulher [...]». Entretanto, esses mecanismos ainda se constituem pouco eficazes perto da amplitude da discriminação/violência cometida contra mulheres, pois, como mencionou Dias (2010, p. 18), «a violência sofrida pela mulher não é exclusivamente de responsabilidade do agressor. A sociedade ainda cultiva valores que incentivam a violência, o que impõe a necessidade de se tomar consciência de que a culpa é de todos»».

Em vista desse cenário e refletindo sobre os encadeamentos internos da língua, alguns questionamentos são suscitados: por que ainda se carrega essa discriminação em nossos discursos? Como pode-se identificar pré-julgamentos mesmo que escamoteados no modo de comunicar-se? A justiça e os seus executores estão discursivamente preparados para falar de violência doméstica sem culpar a mulher? O que se esconde nos encadeamentos internos desses discursos denota, ainda que sem a intenção, preconceito de gênero?

Dessa forma, o presente artigo, ao unir uma causa feminista à ANL, proposta por Oswald Ducrot e Jean- 
Argumentação jurídica e argumentação linguística: quando a língua em uso revela preconceitos

Claude Anscombre (1983), busca investigar e encontrar respostas para a seguinte pergunta norteadora: é possível entrever, através da ANL, possíveis resquícios de enunciação de caráter preconceituoso proferida em sentenças de crimes cometidos contra a mulher?

Para tanto, delimitou-se que seriam analisadas sentenças de crimes punidos com detenção, abarcados pela Lei Maria da Penha, e julgados em uma Comarca de uma região do Rio Grande do Sul. Como há um grande volume de sentenças dessa natureza, estabeleceu-se como critério de recorte que seriam requisitadas as dez últimas sentenças julgadas em cada um dos seguintes anos: 2014, 2015, 2016, 2017 e 2018, perfazendo um total de cinquenta sentenças.

Neste artigo, logo após a introdução, há uma seção destinada à linguagem jurídica e à diferenciação entre o que se entende por argumentação retórica e o que vem a ser a argumentação linguística. Na sequência, especificase o entendimento da ANL para que, na seção seguinte, sejam apresentadas a análise dos excertos retirados das sentenças e obtidos depois de leitura sistematizada, bem como a verificação dos encadeamentos internos que constroem a argumentação. Por fim, o artigo traz as conclusões decorrentes dessa análise, apontando para uma possível interface entre a ANL e a linguagem jurídica apresentada nas sentenças.

\section{A linguagem jurídica diante do poder argumentativo}

Como foi dito na introdução deste trabalho, a linguagem é essencial para a vida em sociedade. Nesse sentido, entende-se que em todas as profissões ela deve ser considerada uma peça fundamental. No caso do cenário jurídico, a linguagem é considerada a ferramenta principal de trabalho, pois, como evidenciaram Moreno e Martins (2006):

A linguagem é o instrumento de todos os operadores jurídicos. É por meio dela que se alça a justiça. Além de ter o direito, você tem que saber expressá-lo de forma precisa, adequada e facilmente compreensível. A Justiça e o Direito materializam-se através da linguagem (Moreno \& Martins, 2006, p. 24).

Tendo a certeza de que o uso da linguagem é realmente importante na esfera jurídica, torna-se imprescindível que os profissionais de Direito tenham amplo domínio da linguagem jurídica, fazendo uso adequado dela a cada contexto comunicativo. Esse domínio não se configura apenas no uso de palavras e de expressões pautadas na norma culta da língua, mas, sim, na utilização de recursos linguísticos de maneira eficiente, de modo a expressar argumentos apropriados à comprovação e à aceitação das teses defendidas.

A linguagem está tão atrelada à justiça e ao direito que, como afirmaram Moreno e Martins (2006),

sem linguagem não há justiça nem Direito. É com a linguagem que os autores da cena judiciária pedem, respondem, replicam, narram, explicam, opinam e decidem. O uso correto e adequado do idioma não é apenas um dos vários instrumentos de trabalho valiosos para o advogado, como o são a capacidade de argumentação, o poder da síntese, o conhecimento do Direito, a cultura geral e o bom senso; ele é o elemento essencial, fundamental e pode ampliar os efeitos dos demais ou, se ausente, diminuí-los sensivelmente (Moreno \& Martins, 2006, p. 24).

Assim, na instância do Direito, tudo é linguagem e é por meio dela que se definirá quem melhor representou os interesses de seus clientes e conseguiu, a partir de seus recursos linguísticos, convencer o juiz. Segundo Moreno 
Argumentação jurídica e argumentação linguística: quando a língua em uso revela preconceitos e Martins (2006, p. 16), pode-se usar a seguinte metáfora para exemplificar isso: «na guerra judicial, o campo de batalha é o processo e as armas são a linguagem e seus inúmeros recursos».

Mas, para que isso ocorra, é importante destacar que o profissional do Direito precisa ter em mente que, ao escolher participar do cenário judicial, sua escrita e seu discurso devem estar sempre voltados a um objetivo principal, pois ele

escreve para obter resultados, e, para isso, precisa mobilizar todos os meios possíveis para alcançar o sucesso. $A$ meta é convencer o leitor. Se for o juiz, o profissional espera uma sentença favorável; se for o advogado adversário, que ele se sinta desestimulado pela argumentação. Tampouco se deve esquecer que o próprio cliente precisa ser convencido de que o advogado utiliza os melhores recursos e as melhores estratégias (Moreno \& Martins, 2006, p. 40).

Entretanto, entende-se que, além de o convencimento ser peça importante na argumentação jurídica, o profissional de Direito também carrega em seu discurso o objetivo de persuadir seu auditório, seus adversários e, principalmente, o juiz durante o embate jurídico. Sobre a diferença entre o entendimento do significado de convencer e de persuadir, que são elementos essenciais dentro da arte de argumentar, Abreu (2009) traçou a seguinte distinção:

Convencer é construir algo no campo das ideias. Quando convencemos alguém, esse alguém passa a pensar como nós. Persuadir é construir no terreno das emoções, é sensibilizar o outro para agir. Quando persuadimos alguém, esse alguém realiza algo que desejamos que ele realize (Abreu, 2009, p. 25).

Buscando recursos e estratégias argumentativas que possam ajudar a obter tanto o convencimento como a persuasão esperados, torna-se questão essencial dominar, não somente o vocabulário especializado, mas também

conhecer todos os recursos expressivos do idioma, as sutilezas semânticas, as ramificações etimológicas que as palavras mantêm entre si e a variada gama de estruturas sintáticas que a língua desenvolveu para caracterizar ênfases, ressalvas e atenuações (Moreno \& Martins, 2006, p. 10).

Partindo disso, a princípio, julga-se que, dentro da estruturação da argumentação jurídica, o que mais parece ser priorizada é a forma como algo vai ser dito diante do público que se faz presente a fim de que esse público acredite em algo ou em alguém. Essa impressão pode estar baseada na retórica antiga que

[...] era, acima de tudo, a arte de falar em público de modo persuasivo; referia-se, pois, ao uso da linguagem falada, do discurso perante uma multidão reunida na praça pública, com o intuito de obter a adesão desta a uma tese que se lhe apresentava (Perelmann \& Tyteca, 1996, p. 6).

E é nesse ponto que se faz necessária a distinção entre o que é entendido como uma argumentação retórica e uma argumentação linguística, pois o que se constata é que a linguagem jurídica se encontra mais propensa a utilizar a argumentação retórica e acaba por não priorizar esse outro viés da argumentação: a estrutura linguística dos argumentos.

Para que se faça essa distinção, primeiramente, é preciso esclarecer que a retórica é uma atividade antiga iniciada na Antiguidade Clássica, quando «era vista como a arte de convencer e persuadir por meio da palavra, fosse escrita, fosse falada. Na Grécia, era uma disciplina indispensável na formação de todos os cidadãos que 
Argumentação jurídica e argumentação linguística: quando a língua em uso revela preconceitos tinham vida ativa na comunidade» (Moreno \& Martins, 2006, p. 35). Contudo, com o passar dos anos, acabou tomando sentido de algo pejorativo, sendo usada para qualificar um texto ou discurso quando ele é «vazio, desnecessariamente enfeitado, cheio de expressões e frases de puro efeito» (Moreno \& Martins, 2006, p. 34). E esse é o tipo de discurso que não pode ser utilizado pelos profissionais do Direito, pois, para que alguém seja convencido e persuadido de algo, é necessário que os argumentos utilizados sejam eficientes e bem estruturados, sem margem para outras interpretações.

Desse modo, para que se entenda o encadeamento desses argumentos, não só de argumentação retórica poderá se fazer um discurso jurídico. Ou seja, é preciso saber que há argumentações intrínsecas na língua que fazem parte de uma outra argumentação: a argumentação linguística.

Ducrot (2009) é quem concebeu essa acepção argumentativa que não condiz com a argumentação retórica. Para esse autor, a argumentação é entendida como «os segmentos de discurso constituídos pelo encadeamento de duas proposições A e C, ligadas implícita ou explicitamente por um conector [...]. Chamarei A o argumento, e $\mathrm{C}$ a conclusão» (Ducrot, 2009, p. 20-21). Nessa nova acepção do verbo argumentar, busca-se o entendimento de que

há encadeamentos argumentativos na própria significação das palavras e dos enunciados com os quais o discurso é feito. Nessas condições, toda palavra, tenha ela ou não alcance persuasivo, faz necessariamente alusão a argumentações. O que mostra no mínimo que não há elo privilegiado entre a argumentação retórica e a argumentação linguística (Ducrot, 2009, p. 23).

Posto isso, entende-se que, na perspectiva da argumentação retórica, a articulação de premissas —que, por sua vez correspondem a uma visão dos fatos - leva à conclusão. Já, para Ducrot, os próprios argumentos, que estão na constituição linguística de um discurso, levam à conclusão e não somente a relação entre premissas e conclusões.

Buscando elucidar ainda mais a ANL e também para que se possa entender melhor como se dá a argumentação interna à língua e como ela é importante na construção de sentidos nos enunciados, a próxima seção traz a teoria proposta por Ducrot e também outros conceitos que serão de grande valia para exemplificar em que consiste a argumentação linguística.

\section{Teoria da Argumentação na Língua (ANL)}

AANL, que tem como precursor Oswald Ducrot, faz a descrição da significação contida no uso da língua, com base nos conceitos de Saussure, que concebe a língua como um

todo por si e um princípio de classificação. Desde que lhe demos o primeiro lugar entre os fatos da linguagem, introduzimos uma ordem natural num conjunto que não se presta a nenhuma outra classificação. A esse princípio de classificação poder-se-ia objetar que o exercício da linguagem repousa numa faculdade que nos é dada pela Natureza, ao passo que a língua constitui algo adquirido e convencional, que deveria subordinar-se ao instinto natural em vez de adiantar-se a ele (Saussure, 2001, p. 17).

Assim, tendo a língua como seu objeto de estudo, Saussure a conceituou como um sistema de relações no qual um signo só se define em oposição a outros signos. Porém, diferente do que sugeriu Saussure, a ANL mostra que, 
Argumentação jurídica e argumentação linguística: quando a língua em uso revela preconceitos além de ser um sistema abstrato, a língua deve ser observada como um sistema passível de uso, pois, para Ducrot (1987) «o objeto de estudo "língua" não pode ser construído sem fazer-se alusão à atividade de fala» (p. 84). Em outras palavras, Ducrot reafirmou a existência de um sistema linguístico, mas enfatizou que o estudo desse sistema deve levar em consideração o uso da língua. Dessa forma, na teoria proposta por Ducrot, há a distinção fraselenunciado ao invés da distinção entre langue e parole desenvolvida nos estudos saussurianos.

Para poder dar conta dessa nova distinção proposta, Ducrot utilizou-se da noção de valor de Saussure, adaptando-a a sua teoria e buscando abarcar as noções de significação e sentido. A primeira diz respeito ao valor semântico da frase, que é considerada abstrata; e a segunda refere-se ao valor semântico do enunciado, que, sendo produto da enunciação, é considerado concreto, empírico e produzido por um locutor (Silva, 2009, p. 86). Ducrot (1987) diferenciou enunciado e frase da seguinte forma:

Assim definido - como fragmento do discurso-, o enunciado deve ser distinguido da frase, que é uma construção do linguista, e que permite dar conta dos enunciados. Na base da ciência linguística há, com efeito, a decisão de reconhecer nos enunciados realizados hic et nunc ${ }^{l}$, todos diferentes uns dos outros, um conjunto de entidades abstratas, as frases, em que cada uma é suscetível de ser manifestada por uma infinidade de enunciados. Fazer a gramática da língua é especificar e caracterizar as frases subjacentes aos enunciados realizados através da língua (Ducrot, 1987, pp. 166-167).

Inspirado nas concepções de Saussure, Ducrot passa a empregar em sua teoria a frase como signo, mostrando que a sua significação só poderá ser compreendida através das possibilidades de combinação com outras frases. As possíveis combinações e ocorrências dessas frases vão resultar em enunciados que são uma manifestação particular e importante de ser observada. A ANL postula a noção de que a argumentação está na língua, intrínseca a ela. Dessa maneira, entende-se que a força argumentativa está no enunciado e que, a partir dele, pode-se desencadear novos sentidos. Como destacou Silva (2009),

[...] a enunciação é o acontecimento que dá vida ao produto, concebido como enunciado. O interesse de Ducrot está justamente nas indicações fornecidas pelo enunciado que trazem o acontecimento enunciativo. Nesse sentido, as marcas da enunciação no enunciado, por ele estudadas, têm a especificidade de remeterem à instância em que tais enunciados são produzidos, fazendo aparecer a posição do locutor, enquanto responsável por esse acontecimento (Silva, 2009, p. 86).

A enunciação, segundo Ducrot (1987, p. 168), é uma aparição momentânea de alguma coisa que não existia antes de se falar e que não existirá mais depois.

Num avanço da própria teoria, Ducrot desenvolveu o conceito de polifonia, que corresponde à ideia de que a enunciação aparece ligada à noção de vários sujeitos: o sujeito empírico, o locutor e o enunciador. O sujeito empírico é o ser que produz o enunciado, e, por isso, «sua determinação não diz respeito ao linguista semanticista, a quem interessa especificamente o sentido do enunciado, o que o locutor diz» (Barbisan, 2007, p. 123). Assim sendo, o locutor é o responsável por aquilo que diz, responsável pela produção do enunciado. De acordo com Barbisan (2007), «o locutor é aquele que responde pelo sentido que constrói em seu discurso. Ele participa de seu dito com marcas de pessoa, tempo e espaço» (p. 123).

\footnotetext{
$\overline{1 .}$ Tradução do latim: «Aqui e agora».
} 
Argumentação jurídica e argumentação linguística: quando a língua em uso revela preconceitos

Já os enunciadores aparecem representados pelas inúmeras vozes e pontos de vista que estão na origem do enunciado, cabendo ao locutor permitir que os enunciadores aconteçam e escolher se identificar com eles, refutálos ou aceitá-los. Ducrot assinalou que enunciadores se expressam através da enunciação,

sem que para tanto se lhe atribuam palavras precisas; se eles «falam» é somente no sentido em que a enunciação é vista como expressando seu ponto de vista, sua posição, sua atitude, mas não, no sentido material do termo, suas palavras (Ducrot, 1987, p. 192).

Como continuação à ANL, Marion Carel, juntamente com Ducrot, desenvolveu a teoria dos blocos semânticos que é definida pela união de dois enunciados através de conectores, chamados assim de encadeamentos argumentativos. Para Ducrot e Carel (2008), «[...] as relações entre signos que estão na base de todo significado, e que são como os átomos da significação ${ }^{2}$, são o que chamamos "encadeamentos argumentativos" ou ainda “argumentações"» (p. 10).

Esses encadeamentos argumentativos podem ser observados em dois aspectos: o normativo e o transgressivo. Quando ocorre um encadeamento normativo, a abreviação fica sendo DC, pois origina-se da palavra francesa donc, que significa portanto em português. Já, nos encadeamentos transgressivos, a abreviação PT vem da palavra, também francesa, pourtant, que significa no entanto em português (Silva, 2009, p. 92). Para exprimir a diferença entre esses aspectos, Barbisan (2007, p. 127) utilizou o seguinte exemplo: «João está com pressa de chegar DC corre; e: João está com pressa de chegar PT não corre». No primeiro segmento, observa-se o aspecto normativo e, no segundo, o aspecto transgressivo. Assim, segundo a mesma autora:

Os dois aspectos exprimem a mesma ideia: a de correr em razão da pressa. O normativo e o transgressivo não são mais do que dois aspectos da mesma ideia, em que o transgressivo só é transgressivo porque transgride o normativo (Barbisan, 2007, p. 127).

Contudo, além da concepção de aspectos discursivos, esses encadeamentos argumentativos ligados ao conceito de polifonia, já mencionado anteriormente, evidenciam que em um mesmo enunciado, proferido por determinado locutor (L), pode-se, através da organização linguística utilizada, distinguir diferentes enunciados e enunciadores (E), pois:

No que concerne à teoria da polifonia, ela acrescenta a essa alteridade, por assim dizer «externa», uma alteridade «interna», colocando que o sentido de um enunciado descreve a enunciação como uma espécie de diálogo cristalizado, em que várias vozes se entrechocam (Ducrot, 1987, p. 9).

Assim sendo, a ANL pode expor os encadeamentos linguísticos e, consequentemente, auxiliar no entendimento dos discursos, não deixando margem para produções de sentido contrários aos daquele que se quer dizer. Por essa razão, essa teoria foi escolhida para que, através dela, fosse possível entrever vestígios de enunciação implícita de caráter preconceituoso proferida em sentenças de delitos cometidos contra a mulher.

$\mathrm{Na}$ seção seguinte, encontra-se a metodologia adotada para que esta pesquisa pudesse fazer uso da ANL e,

2. $\quad$ Na fase inicial da teoria dos blocos semânticos, significação e sentido eram assumidas como sinônimos. No atual estágio das pesquisas, não mais. Entretanto, como esse não é o foco desta investigação, recomenda-se, para maior aprofundamento, a leitura de Drucrot e Carel (2008). 
Argumentação jurídica e argumentação linguística: quando a língua em uso revela preconceitos consequentemente, entrever os enunciadores que são evidenciados na organização argumentativa das sentenças analisadas.

\section{Metodologia}

Esta pesquisa tem caráter qualitativo, pois busca investigar como se estrutura a argumentação jurídica, a fim de verificar se há enunciados com possíveis resquícios de preconceito contra o gênero feminino em casos de violência doméstica, pautando-se na ANL.

Como corpus de análise para esta pesquisa, foram utilizadas sentenças de delitos punidos com detenção, abarcados pela Lei Maria da Penha, julgados nos últimos cinco anos em uma Comarca do Rio Grande do Sul. Essa escolha se deu por ser na sentença em que o uso da língua se molda para a tomada de decisão.

Para a delimitação do corpus, selecionaram-se as dez últimas sentenças julgadas em cada um dos seguintes anos: 2014, 2015, 2016, 2017 e as julgadas no início de 2018, perfazendo um total de cinquenta (50) sentenças requisitadas e analisadas.

A análise da organização argumentativa, sob a perspectiva da ANL, foi feita através da leitura das sentenças e da busca por evidências de preconceito contra o gênero feminino nesses enunciados, muito embora se espere que nesses textos — devido à sua finalidade - haja a defesa da mulher e nenhuma propagação de preconceitos que, como se sabe, ainda são cultivados pela sociedade.

Na próxima seção, encontram-se os excertos das sentenças seguidos das análises desenvolvidas.

\section{Análise da organização interna da argumentação jurídica}

Para que esta pesquisa pudesse ser concretizada, 50 sentenças foram requisitadas e analisadas ${ }^{3}$. Desse número inicial, obteve-se, numa primeira leitura, um total de 9 sentenças que continham algum tipo de estrutura linguística com resquícios de preconceito. Já as outras 41 sentenças foram eliminadas, pois se constatou que não continham passagens com essa característica.

Das 9 sentenças remanescentes, foram retirados 10 excertos para análise mais aprofundada. No seguinte quadro, encontra-se o total de sentenças que foram analisadas, para que, na sequência, se apresente a análise das estruturas enunciativas dessas sentenças:

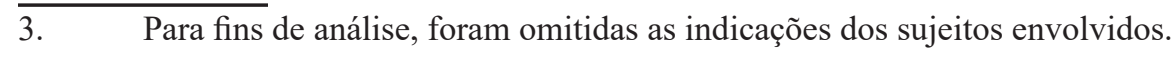




\begin{tabular}{|c|c|c|}
\hline Ano & Quantidade de sentenças & Numeração \\
\hline 2014 & 03 & $0114,0214,0314$ \\
\hline 2015 & 04 & $0115,0215,0315,0415$ \\
\hline 2016 & - & - \\
\hline 2017 & 02 & 0117,0217 \\
\hline 2018 & - & - \\
\hline
\end{tabular}

Quadro 1. Seleção do corpus

Análise dos enunciados dos trechos das sentenças:

—Sentença 0214 (Improcedente)

Locutor 1: «Ainda, disse não possuir mais interesse no prosseguimento do feito, inclusive tendo retomado 0 relacionamento com o acusado.»

—Sentença 0314 (Improcedente)

Locutor 1:«Em prosseguimento, passado ao debate oral, o Ministério Público, alegando o desinteresse da vítima no prosseguimento do feito, inclusive tendo retomado o relacionamento com o acusado, requereu a improcedência da ação penal, com o que anuiu a defesa.»

Os enunciados acima permitem as possíveis combinações de enunciadores:

(E1) retomar o relacionamento com o acusado DONC desinteressar-se no prosseguimento do feito.

(E2) (-neg) $)^{4}$ retomar o relacionamento com o acusado DONC (-neg) desinteressar-se no prosseguimento do feito.

(E3) (-neg) retomar o relacionamento com o acusado DONC desinteressar-se no prosseguimento do feito.

(E4) retomar o relacionamento com o acusado DONC (-neg) desinteressar-se no prosseguimento do feito.

O uso do «ainda», nesse contexto, dá a entender que o Locutor (L) concorda com E1 e E2, deixando evidente que a retomada do relacionamento é uma razão plausível para haver o desinteresse pela causa.

Ou seja, dentro dessa construção argumentativa, há incidência de enunciadores que revelam que a continuação ou não do envolvimento amoroso pela mulher pode, de alguma forma, intervir na maneira como um caso desses será julgado. Nesse caso, vê-se que a retomada do relacionamento por parte da vítima mulher é suficiente para que a justiça não dê seguimento à condenação do agressor. Ou seja, a justiça parte do pressuposto de que a vítima deve querer continuar o processo litigioso para que haja algum tipo de condenação contra o agressor. Ainda que seja essa a forma como a justiça opera no Brasil e ainda que esses argumentos não sejam suficientes para afirmar que esteja havendo, em casos como esse, deliberado preconceito contra a mulher, é possível entrever pela cadeia

4. $\quad$ (-neg) sentido de negação. 
Argumentação jurídica e argumentação linguística: quando a língua em uso revela preconceitos argumentativa que, nesses contextos, a justiça se exime de defender a mulher, mesmo tendo havido agressão contra ela. Em ambas as sentenças em análise, o juiz deliberou como improcedente a ação.

-Sentença: 0115 (improcedente)

Locutor 1:«(testemunha) declarou ter presenciado um dos fatos (16/12/2014), quando a vítima teria ido buscar alguns pertences na residência do acusado, oportunidade em que este teria declarado não querer mais a presença da vítima no local e «que o que é teu tá guardado», momento em que a vítima teria dito que somente foi ao local para buscar os documentos, iniciando-se uma discussão, com troca de ofensas, próprias de um relacionamento desgastado ou findo.»

Ao utilizar a expressão «próprias de um relacionamento desgastado ou findo», o locutor dá espaço para que se apresente um E1 que toma um relacionamento acabado como modelo para as trocas de ofensas.

(E1) relacionamento desgastado ou findo DONC início de uma discussão, com trocas de ofensas.

(E2) (-neg) relacionamento desgastado ou findo DONC (-neg) início de discussão, com trocas de ofensas.

Além disso, a utilização da palavra «próprias» dá ao enunciado a possibilidade de se entrever o E3, no qual evidencia-se que há algumas ofensas que são próprias de um relacionamento desgastado ou findo e outras que não são.

(E3) há ofensas que são próprias de um relacionamento desgastado ou findo DONC há outras ofensas que não são.

A partir desses argumentos, entende-se que, por ser um texto no qual a defesa da mulher deveria estar presente, não há como se deixar espaço para que entendimentos contrários sejam enunciados. Isso porque, ao enunciar que algumas ofensas são próprias de certos tipos de relacionamento, o locutor abre espaço para que se compreenda o argumento de outra forma, relacionando-o à ideia de que há ofensas contra a mulher que são justificáveis por ser proferidas nos relacionamentos findos. Assim, explicita-se o entendimento de que se deve relevar a falta de respeito e eventuais ofensas contra a mulher em alguns contextos, já que o relacionamento está para acabar. Ainda que não seja deliberada a intenção do sujeito empírico de concordar com essa ideia, é possível perceber uma certa leniência em relação a certos tipos de ofensas proferidas contra a mulher.

Nessa mesma sentença 0115 , encontra-se outro trecho no qual foi utilizada outra expressão que merece análise e que se repete na sentença 0117 .

Locutor 1: «A ameaça para perfectibilizar o tipo do artigo 147 do Código Penal, deve ser real, concreta e séria, o que não se verifica no caso concreto, já que, eventual palavra ameaçadora, se ocorreu, foi proferida no calor de discussão, não restando suficientemente comprovada a consistência das palavras supostamente proferidas pelo acusado, necessárias e indispensáveis à caracterização do delito de ameaça.»

—Sentença: 0117 (improcedente)

Locutor 1: «Desinteressada no prosseguimento da ação penal e pouco recordando dos fatos, a ofendida limitou-se a referir que discutiam muito em razão da ex-esposa do réu, fazendo referências a diversos xingamentos e algumas ameaças proferidas no calor de discussões.»

A expressão «proferida no calor de discussão» utilizada nas duas sentenças acima abre espaço para que se 
Argumentação jurídica e argumentação linguística: quando a língua em uso revela preconceitos

apresente o encadeamento argumentativo em que um dos enunciadores concorda com o ponto de vista de que, durante o calor de uma discussão, alguma palavra ameaçadora pode ocorrer e isso deva ser encarado como uma situação trivial.

É o que se vê nos encadeamentos a seguir:

(E1) (-neg) calor da discussão DONC (-neg) xingamentos e ameaças são tolerados.

(E2) calor da discussão DONC xingamentos e ameaças proferidas.

Novamente, em se tratando de um texto cuja finalidade seja o julgamento de um delito praticado contra a mulher, o uso de um substantivo que imprime a ideia de intensidade da discussão, como a palavra «calor», pode deixar o enunciado implicitamente conivente com discussões que, passando do limite, abram margens para xingamentos e ameaças, o que não parece apropriado em contextos como os que se propõem a defender a mulher. Dessa maneira, adjetivar uma discussão como calorosa e se pautar nessa ideia para justificar discussões e ameaças contra a mulher não parece ser apropriado em uma sentença cujo propósito é justamente defendê-la.

-Sentença: 0215 (parcialmente improcedente)

Locutor 1: «Não há qualquer demonstração de que a vítima tenha provocado injustamente o agressor previamente a justificar o agir desproporcional de [réu $]^{5}$. Discussão não gera incidência da referida redutora. Ademais, o ânimo alterado do réu não tem condão de tornar atípica a conduta, ou reduzir a pena.»

Desse excerto podem-se descrever os seguintes enunciadores:

(E1) (-neg) demonstração de provocação injusta da vítima DONC sem justificativa para ação desproporcional.

Em E1, entende-se que sem qualquer demonstração de provocação injusta o agir desproporcional do agressor não pode ser justificado. Dessa forma, pode-se depreender o seguinte enunciador:

(E2) demonstração de provocação injusta da vítima DONC justificativa para ação desproporcional.

Ainda que o locutor não tenha intenção de se identificar com o E2, em sua construção argumentativa, há o ponto de vista desse enunciador E2, que explicita o seguinte questionamento: se a vítima tivesse provocado o agressor, uma ação desproporcional se justificaria?

- Sentença: 0315 (procedente)

Locutor 1: «No caso dos autos, ainda que tenha ocorrido prévia discussão entre o casal, a violência física perpetrada pelo réu contra a vítima não se justifica. Não me parece razoável pensar que uma briga conjugal, seja pelo motivo que for, justifique conduta tão agressiva e desproporcional por parte do réu, mormente tratando-se de violência contra mulher, esta seguramente parte mais frágil da relação.»

No trecho acima, o locutor faz uso da expressão «seguramente parte mais frágil da relação» referindo-se à mulher que foi agredida. Mesmo sabendo da importância das leis para a proteção da mulher e de como isso se faz necessário diante de tanto preconceito, agressão e violências sofridas diariamente, o uso dessa expressão acaba levando a outros entendimentos, ou seja, a enunciadores que revelam ainda mais o preconceito que justamente se tenta eliminar:

(E1) a mulher é a parte mais frágil da relação DONC ainda é agredida.

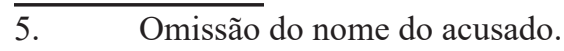


Argumentação jurídica e argumentação linguística: quando a língua em uso revela preconceitos

(E2) ser mulher e frágil DONC ser passível de agressão.

Referir-se à mulher como a parte frágil da relação, nessa e em outras sentenças em que essa conotação também foi utilizada, dá espaço a enunciadores com o ponto de vista de que não se está pensando na conduta agressiva e desproporcional do homem, mas sim, que a atitude foi descompensada por ser a mulher um ser frágil. Ou seja, tirou-se o foco da responsabilidade do agressor e colocou-se sobre a parte assumida como frágil: a mulher. Dessa forma, parece ficar evidente, pelo argumento linguístico, que a procedência da sentença se dá não somente pelo fato de a conduta do réu ser inaceitável, mas adicionou-se ao veredito o argumento de que a mulher foi frágil e, portanto, passível de agressão. Ainda que se tenha intenção de defesa da mulher, esse argumento reforça a ideia de que mulheres e homens não têm papéis iguais em um relacionamento.

Outro fator relevante desse trecho é o uso da palavra «desproporcional», pois o locutor assumeu que nada justifica «conduta tão agressiva e desproporcional por parte do réu». Assim, surge a dúvida: a proporcionalidade de uma conduta agressiva pode ser justificada?

Diante desse questionamento, evidenciam-se os seguintes enunciadores:

(E1) conduta agressiva e desproporcional DONC conduta injustificável.

(E2) conduta (-neg) agressiva e (-neg) desproporcional DONC conduta justificável.

Diante desses enunciadores, percebe-se que o locutor assume E1, mas ainda carregou em seu discurso o conteúdo argumentativo que E2 enunciou. Isso evidencia que pode haver, sim, a aceitação de uma proporcionalidade justificada dentro de uma conduta agressiva.

—Sentença: 0217 (parcialmente procedente)

Locutor 1: «Ademais, ainda que tivesse agido em defesa pessoal, não deveria ter lesionado [vítima] de forma tão considerável, de modo desproporcional, demonstrando total excesso na defesa. Não é razoável pensar que prévio desentendimento, seja pelo motivo que for, justifique conduta tão agressiva por parte do réu, mormente tratando-se de violência contra mulher, esta seguramente parte mais frágil da relação.»

No trecho acima, novamente há uso da expressão «parte mais frágil da relação». Além disso, o excerto traz outro encadeamento a se observar que é o seguinte: «não deveria ter lesionado (a vítima) de forma tão considerável, de modo desproporcional, demonstrando total excesso na defesa».

Novamente há o uso da palavra «desproporcional» que, como já foi mencionado anteriormente, abre espaço para outras significações.

Desse trecho evidenciam-se os seguintes enunciadores:

(E1) lesionou (a vítima) de forma tão considerável DONC demonstrou total excesso na defesa.

(E2) (-neg) lesionou (a vítima) de forma tão considerável DONC empregou defesa pessoal.

Desses dois enunciadores, desdobra-se outro:

(E3) poderia ter lesionado POURTANT (-neg) de forma tão considerável.

Ao estabelecer essa estrutura argumentativa, o locutor, mesmo que sem intenção, acaba trazendo em seu enunciado resquícios de preconceito, pois pode-se antever pelo enunciador E2 que, se a lesão não tivesse sido tão considerável, poderia ser considerada legítima defesa. 
Argumentação jurídica e argumentação linguística: quando a língua em uso revela preconceitos -Sentença: 0415 (procedente)

Locutor 1: «Se não bastasse, muito pouco provável que a ex-esposa fosse arranjar todo um cenário de crise, perder tempo, importunar vizinhos e acionar a autoridade policial para a mera finalidade de prejudicar o sujeito. Isso até acontece, excepcionalmente. Todavia, a gravidade do caso posiciona as alegações em situação de verossímeis, face todas as circunstâncias objetivas concatenadas.»

Ao produzir o enunciado «isso até acontece, excepcionalmente» em relação às mulheres que inventam fatos para prejudicar o ex-marido, o locutor se coloca na posição de um enunciador que acredita que isso acontece, mesmo não sendo esse o caso nessa sentença.

(E1) existem mulheres que (-neg) arranjam todo um cenário de crise DONC são passíveis de amparo jurídico.

(E2) existem mulheres que arranjam todo um cenário de crise DONC (-neg) são passíveis de amparo jurídico.

Enunciando esse tipo de construção, o locutor acabou se identificando tanto com o enunciador E1, quanto com o enunciador E2. Ao proferir tal enunciado, dentro de um contexto como esse, o locutor, mesmo que sem intenção, colocou-se na posição de um propagador de velhas suposições sociais, neste caso, a suposição de que as mulheres inventam cenários para que seus maridos sejam acusados. Assim, entende-se que a utilização do advérbio «excepcionalmente» abre espaço para interpretações que fogem ao caso tratado no momento.

Para finalizar esta seção de análise, apresenta-se o seguinte excerto que foi retirado de uma sentença do ano de 2014.

Sentença 0114: (procedente)

Locutor 1: «Quanto ao comportamento da vítima, pelo que se depreende do conjunto probatório, em nada colaborou para o cometimento do delito.»

Esse enunciado deixa entrever que há situações em que o comportamento da vítima pode colaborar para o cometimento do delito.

(E1) bom comportamento da vítima DONC (-neg) colaboração para o cometimento do delito.

(E2) (-neg) bom comportamento da vítima DONC colaboração para o cometimento do delito.

Dos enunciadores acima, entende-se que o locutor se identificou com o E1, porém, pela análise do encadeamento dos argumentos, pode-se entrever que o enunciador E2 está também evidente em seu enunciado.

Esse enunciado se assemelha à organização argumentativa do excerto 0515, deixando entrever uma ideia de que a violência contra a mulher resulta do bom ou mau comportamento dela junto a seu agressor. Ou seja, a responsabilidade do delito parece não recair somente sobre o acusado. Nos argumentos evidenciados nos encadeamentos, deixa-se explícita a ideia de que a agressão contra a mulher depende também de seu bom ou mau comportamento. No exemplo em análise, novamente, reforça-se: é bem provável que associar a agressão ao comportamento da vítima não tenha sido a intenção do juiz ao proferir a sentença.

Em outras palavras, utilizar o comportamento como algo que possa colaborar para o cometimento de um delito é recriar os modelos mais antigos de submissão feminina. Dessa forma, a utilização da expressão «comportamento da vítima» para justificar ou não o delito suscita a perpetuação de preconceitos enraizados 
Argumentação jurídica e argumentação linguística: quando a língua em uso revela preconceitos socialmente. Comportamentos não colaboram para delitos, o que colabora para delitos são desvios de caráter e sentimentos possessivos.

Com as análises realizadas, constataram-se alguns resquícios de enunciação de caráter preconceituoso em sentenças de delitos cometidos contra as mulheres, confirmando, assim, que a ANL auxilia na explicitação da argumentação linguística. Pôde-se evidenciar enunciados e, consequentemente, enunciadores que exprimem estruturas enunciativas que vão além do que é dito pelo locutor e que carregam preconceitos que talvez fossem imperceptíveis em uma análise argumentativa não linguística. Assim, a presente análise revela cadeias de significados descortinados pela argumentação interna dos enunciados que, por seus encadeamentos argumentativos, acabam perpetuando sentidos de caráter preconceituoso.

\section{Conclusões}

Por meio deste estudo, identificou-se que realmente há uma interface entre a ANL e a linguagem jurídica elucidada pela análise das sentenças. Essa interface foi evidenciada ao se confirmar que, na argumentação linguística utilizada em sentenças de delitos punidos com detenção, abarcados pela Lei Maria da Penha e julgados nos últimos cinco anos em uma Comarca do Rio Grande do Sul, existem resquícios de discursos com preconceito de gênero.

Por meio de uma metodologia de análise dos encadeamentos argumentativos, identificou-se que o sujeito empírico pode ter uma intenção estabelecida quando se coloca na posição de locutor — nesse caso a de defesa da mulher-, mas na concretização desse enunciado, ou seja, na enunciação, são evidenciados enunciadores que divergem dessas intenções do sujeito empírico, revelando posições contrárias à defesa da mulher. A partir disso, entende-se que pré-julgamentos ainda são difundidos em discursos jurídicos, disseminando a discriminação de gênero em enunciados que têm como finalidade, justamente, a defesa da mulher.

Contudo, também se verificou que a justiça e seus executores estão se mostrando discursivamente mais bem preparados para falar de violência doméstica sem culpar a mulher, pois, no conjunto de sentenças recolhido, não houve um grande número de exemplos para a análise que se propôs. Por outro lado, os enunciados encontrados são suficientes para indicar que ainda há o que ser feito.

Assim, apesar dos grandes avanços obtidos, como a própria Lei Maria da Penha, é preciso ir além. E nesse escopo está a argumentação linguística que pode contribuir muito para que, entendendo melhor o funcionamento dos encadeamentos argumentativos da língua, não se continue perpetuando discursos que evidenciem preconceito, seja ele qual for. 


\section{Referências bibliográficas}

1. Abreu, A. S. (2009). A arte de argumentar: gerenciando razão e emoção. Cotia: Ateliê Editorial.

2. Barbisan, L. B. (2007). Uma proposta para o ensino da argumentação. Letras de Hoje, 42(1), 111-138. http:// revistaseletronicas.pucrs.br/ojs/index.php/fale/article/view/2415/1889

3. Brasil. (2006). Lei $n^{0} 11.340$, de 7 de agosto de 2006. Cria mecanismos para coibir a violência doméstica e familiar contra a mulher... Diário Oficial da União, Brasília, DF, 7 de agosto, 2006.

4. Dias, M. B. (2010). A Lei Maria da Penha na justiça: a efetividade da Lei 11.340/2006 de combate à violência doméstica e familiar contra a mulher. São Paulo: Editora Revista dos Tribunais.

5. Ducrot, O. \& Carel, M. (2008). Descrição argumentativa e descrição polifônica: o caso da negação. Letras de Hoje, 43 (1), 7-18. http://revistaseletronicas.pucrs.br/ojs/index.php/fale/article/view/2865/2804

6. Ducrot, O. (1987). O dizer e o dito. São Paulo: Pontes.

7. Ducrot, O. (1981). Provar e dizer: linguagem e lógica. São Paulo: Global Ed.

8. Ducrot, O. (2009). Argumentação retórica e argumentação linguística. Letras de Hoje, 44(1), 20-25. http:// revistaseletronicas.pucrs.br/ojs/index.php/fale/article/view/5648/4116

9. Moreno, C. \& Martins, T. (2006). Português para convencer: comunicação e persuasão em direito. São Paulo: Ática.

10. Perelman, C. \& Tyteca, L. (1996). Tratado da argumentação: a nova retórica. São Paulo: Martins Fontes. 11. Saussure, F. de. (2001). Curso de linguística geral. São Paulo: Editora Cultrix.

12. Silva, C. L. da C. (2009). Argumentação e ensino de língua materna. En Silva, C. L. da C., Toldo, C. S., Barbisan, L. B. \& Marquardt, L. L. (Eds.). Teorias do discurso e ensino. Porto Alegre: EDIPUCRS. 